\title{
Similar Roles of Substantia Nigra and Ventral Tegmental Dopamine Neurons in Reward and Aversion
}

\author{
Anton Ilango, ${ }^{1}$ Andrew J. Kesner, ${ }^{1}$ Kristine L. Keller, ${ }^{1}$ Garret D. Stuber, ${ }^{2}$ Antonello Bonci, ${ }^{1}$ and Satoshi Ikemoto ${ }^{1}$ \\ ${ }^{1}$ Intramural Research Program, National Institute on Drug Abuse, National Institutes of Health, U.S. Department of Health and Human Services, Baltimore, \\ Maryland 21014, and 2Department of Psychiatry, University of North Carolina at Chapel Hill, Chapel Hill, North Carolina 27599
}

\begin{abstract}
Dopamine neurons in the ventral tegmental area (VTA) are implicated in affective functions. However, it is unclear to what extent dopamine neurons in substantia nigra pars compacta $(\mathrm{SNc})$ play such roles. TH-Cre transgenic mice received adeno-associated viral vectors encoding channelrhodopsin2 (ChR2), halorhodopsin (NpHR), or control vector into the VTA or SNc, resulting in selective expression of these opsins in dopamine neurons. Mice with ChR2 learned instrumental responding to deliver photostimulation into the VTA or SNc and also sought for the compartment where they received photostimulation (i.e., operant place preference). Operant place preference scores were highly correlated with self-stimulation responses. In contrast, mice with NpHR avoided the compartment where they received photostimulation into the VTA, SNc, or dorsal striatum, whereas control mice did not. These observations suggest that the excitation and inhibition of SNc dopamine neurons elicit positive and negative affective effects, respectively, similar to those of VTA dopamine neurons.
\end{abstract}

Key words: dopamine; dorsal striatum; drug abuse; Parkinson's disease; substantia nigra; ventral tegmental area

\section{Introduction}

Dopamine (DA) neurons in the ventral tegmental area (VTA) are thought to play important roles in motivation and reward (Ikemoto, 2007). Pharmacological studies showed that rewarding effects of many abused drugs, including psychostimulant drugs, are mediated by DA neurons localized in the VTA projecting to the ventral striatum and limbic cortices (i.e., the mesolimbic DA system; Fibiger and Phillips, 1986; Koob, 1992; Robbins and Everitt, 1996). Consistently, animals intracranially self-administer DAergic drugs into the projection regions of VTA DA neurons (Ikemoto, 2007). Moreover, optogenetic studies showed that the excitation of VTA DA neurons induces conditioned place preference in mice (Tsai et al., 2009), and mice and rats learn instrumental responding to excite VTA DA neurons (i.e., intracranial self-stimulation, ICSS; Adamantidis et al., 2011; Witten et al., 2011; Kim et al., 2012).

The mesolimbic DA system also plays a role in negative affect. Conditioned place aversion is induced by injections of the $\mathrm{D}_{2}$ receptor agonist quinpirole into the VTA (Liu et al., 2008), which inhibit activity of VTA DA neurons, or injections of $\mathrm{D}_{1}$ receptor

\footnotetext{
Received April 23, 2013; revised Nov. 21, 2013; accepted Nov. 26, 2013.

Author contributions: A.I. and S.I. designed research; A.I., A.J.K., and K.L.K. performed research; G.D.S. and A.B. contributed unpublished reagents/analytic tools; A.I. and S.I. analyzed data; A.I. and S.I. wrote the paper.

This work was supported by the Intramural Research Program of National Institute on Drug Abuse, National Institutes of Health. We thank the NIDA-IRP Optogenetics and Transgenic Technology Core for providing viral vectors, the Microscopy Core for imaging help, and Drs Jennifer Bossert, Ikue Kusumoto, and Ross McDevitt for technical assistance.

The authors declare no competing financial interests.

Correspondence should be addressed to Dr Satoshi Ikemoto, NIDA-IRP, 251 Bayview Boulevard, Suite 200, Baltimore, MD 21224. E-mail: satoshi.ikemoto@nih.gov.

DOI:10.1523/JNEUROSCI.1703-13.2014

Copyright $\odot 2014$ the authors $\quad 0270-6474 / 14 / 340817-06 \$ 15.00 / 0$
}

antagonists into the ventral striatum (Shippenberg et al., 1991). Moreover, optogenetic inhibition of VTA DA neurons (Tan et al., 2012) or optogenetic excitation of midbrain GABA neurons that inhibit VTA DA neurons elicits aversion (Stamatakis and Stuber, 2012; Tan et al., 2012; Jhou et al., 2013).

The lateral counterpart to the mesolimbic DA system is the nigrostriatal DA system, in which substantia nigra pars compacta (SNc) DA neurons project to the dorsal striatum (DStr). This system plays important roles in sensorimotor functions including motor execution and habit formation (Haber, 2003). Some studies suggest affective and motivational role of this DA system (Wise, 2009), and recent optogenetic studies begin to provide strong evidence. Mice learn ICSS with excitation of SNc DA neurons (Rossi et al., 2013) or DStr neurons expressing $\mathrm{D}_{1}$ receptors (Kravitz et al., 2012). However, it has not yet been examined whether inhibition of SNc DA neurons or their projections to the DStr induces aversion. The present study compared VTA and SNc DA neurons for their affective functions to determine the extent to which SNc DA neurons play roles in such functions.

\section{Materials and Methods}

Adult male tyrosine hydroxylase (TH)::IRES-Cre knock-in mice (Lindeberg et al., 2004) crossed with C57/BL/7j (weighing 24-35 g at the time of surgery) were used. They were individually housed in a colony maintained with a $12 \mathrm{~h}$ light/dark cycle (lights on at 07:00 A.M.), and had ad libitum access to food and water except during testing. All procedures were approved by the Animal Care and Use Committee of the Intramural Research Program, National Institute on Drug Abuse and were in accordance with the National Research Council Guide for the Care and Use of Laboratory Animals.

Viral vectors. The NIDA Optogenetics and Transgenic Technology Core produced adeno-associated virus serotype-1 (AAV) encoding channelrhodopsin-2 (ChR2), halorhodopsin-3.0 (NpHR) and enhanced 
yellow fluorescent protein (EYFP) from plasmids obtained from the Stanford Optogenetics Innovation Laboratory (pAAV-Ef1a-DIOhChR2(H134R)-EYFP-WPRE-pA, pAAV-Ef1a-DIO-eNpHR3.0-EYFPWPRE-pA, and pAAV-Efla-DIO-EYFP-WPRE-pA). The final viral concentrations were $6.3 \times 10^{12}, 1.9 \times 10^{12}$, and $2.3 \times 10^{12}$ viral-genomes/ml for ChR2, NpHR, and EYFP, respectively.

Stereotaxic surgery. Mice were anesthetized with ketamine/xylazine mixture (80/12 mg/kg, i.p.) for stereotaxic surgeries. Injection/opticfiber implantation surgeries were performed unilaterally for Experiments $1-3$ and bilaterally for Experiment 4 . The coordinates for viral vector injections were as follows: AP $3.5 \mathrm{~mm}$ posteriorly from bregma, ML $0.5 \mathrm{~mm}$ laterally from midline, DV $4.0 \mathrm{~mm}$ ventrally from the dorsal surface of the brain for the VTA; AP 3.1, ML 1.6, DV 4.0 for the SNc; AP -0.8 , ML 1.3, DV 3.0 for the medial part of DStr (mDStr); and AP -0.9 , ML 2.0, DV 2.6 for the central part of DStr (cDStr). One of the viral vectors (Experiments 1,3: $1 \mu \mathrm{l}$; Experiment 3: 0.2-0.3 $\mu \mathrm{l}$; Experiment 4: $0.5 \mu \mathrm{l}$ ) was microinjected by a syringe pump over $10 \mathrm{~min}$ into the VTA or $\mathrm{SNc}$, with additional $10 \mathrm{~min}$ before removal of the injection needle (33 gauge). Then, optic fibers ( $200 \mu \mathrm{m}$ core size with numerical aperture of 0.37 ), which were constructed as described previously (Sparta et al., 2012), were chronically implanted $0.2 \mathrm{~mm}$ dorsal to the injection site and secured on the skull with dental cement. Behavioral experiments were started $\sim 1$ (Experiments 1-3) or 2 (Experiment 4 ) months after surgery, to allow gene expression.

Behavioral apparatus. All behavioral experiments were conducted in standard operant conditioning chambers (Med Associates). Each chamber was equipped with two levers, two cue lamps, a house lamp, an audio stimulus generator, and four pairs of infrared detectors. Mice were gently connected to the patch cable that was connected to either a $473 \mathrm{~nm}$ laser for ChR2 or $532 \mathrm{~nm}$ laser for NpHR via an optical swivel. Computer software controlled a pulse generator that controlled lasers.

ICSS test. ICSS experiments were conducted using mice that received ChR2 or control vectors. Each session lasted for $30 \mathrm{~min}$, and sessions were typically separated by $1 \mathrm{~d}$. To facilitate the acquisition of lever pressing during the first 11 sessions, a response on the right ("active") lever illuminated a cue lamp for $1 \mathrm{~s}$ just above the lever, whereas a response on the left ("inactive") had no programmed consequence. In session 12 and subsequent sessions, no cue was provided, to eliminate possible potentiating effects of visual stimuli (Shin et al., 2010; Keller et al., 2013). To assess baseline response levels, intracranial photostimulation was not provided during the first two sessions. During sessions 3-7, active lever pressing was rewarded with an intracranial train of 15 light pulses ( $10 \mathrm{~ms}$ pulse duration delivered at $25 \mathrm{~Hz}$ ) via the implanted optic fiber. These acquisition sessions were followed by four extinction sessions during which active lever pressing delivered no photostimulation. Thereafter, four reacquisition sessions were performed with photostimulation (sessions 12-17). In addition, the mice received a lever reversal test over three sessions in which the assignment of active and inactive levers with respect to the right and left levers was reversed in second and third sessions without any cue. Mice used in Experiment 2 only went through up to session 7, and in session 8, they were killed for c-Fos expression, 60 min after a 30 min ICSS session.

Operant place preference test. The test chamber described above with levers retracted was divided into two equal size compartments by placing a Plexiglas barrier with the height of $12 \mathrm{~mm}$ from the grid floor. To further help mice to distinguish between the compartments, a $5 \mathrm{kHz}$ tone was continuously delivered when mice were in the right compartment, while a $10 \mathrm{kHz}$ tone in the left. ChR2 mouse received a 20-pulse train (10 ms pulse duration delivered at $25 \mathrm{~Hz}$ ) in each second, whereas NpHR and control mice received "continuous" photostimulation via the implanted optic fiber as long as they stayed in one of the compartments. They received photostimulation in the right compartment during the first four sessions and in the left during the last four sessions, while keeping the assignment of tones to the same throughout the experiment. Each session lasted for $30 \mathrm{~min}$, and sessions were typically separated by $1 \mathrm{~d}$. Each session's place preference scores (PPSs) were derived in two ways: PPSright, by subtracting time spent in the left compartment from time spent in the right compartment; and PPS-stimulation, by subtracting time spent in nonstimulation compartment from that in stimulation com- partment. Overall PPSs were derived by adding PPS-stimulation over eight sessions.

Histology. After completion of the behavioral experiment, all animals were intracardially perfused with ice-cold $0.9 \%$ saline followed by $4 \%$ paraformaldehyde. Brains were coronally sectioned at $50 \mu \mathrm{m}$. Some brain sections were processed for immunohistochemistry detecting c-Fos or colocalization of EYFP and TH. These proteins were detected by rabbit anti-cFos (1:2000; no. AB152MI, Santa Cruz Biotechnology), goat anti-GFP/YFP (1:1500; no. A11120, Life Technologies) and rabbit anti-TH (1:1500; no. AB152, EMD Millipore) with goat anti-rabbit secondary-antibody AlexaFluor 568, donkey anti-goat AlexaFluor 488 and donkey anti-rabbit AlexaFluor 594 (1:200; Life Technologies). Mounted sections were coverslipped with DAPI nuclear counterstain (no. H-1200, Vector Laboratories). Optical fiber placements and EYFP expression were determined with fluorescent microscopy.

Cell-count procedures. c-Fos expression was captured with a $5 \times$ lens on a fluorescent-microscope/video/computer system and quantified $300 \times$ $300 \mu \mathrm{m}$ areas over the SNc or VTA (Fig. $1 H$ ) with iVision-Mac (Biovision). To determine what percentage of VTA dopamine neurons expressed ChR2 with SNc injections, we traced the VTA images captured by a fluorescent-microscope/video/computer system with a $10 \times$ lens, identified TH- and EYFP-expressing cells with a $40 \times$ lens, using Neurolucida (MBF Bioscience). To determine what percentage of SNc EYFP-expressing neurons were dopaminergic, we captured EYFP- and TH-expressing cells in the SNc with a $10 \times$ lens of the Zeiss LSM710 confocal microscope, and the images were analyzed by ImageJ (http://imagej.nih.gov/ij/).

Statistical analyses. For ANOVAs, data on lever pressing and crossing are square-root transformed, to minimize heterogeneous variances for parametric statistical tests (McDonald, 2009). When Mauchley's test detected violation of the sphericity assumption for repeated factors, the degrees of freedom for respective tests were adjusted with the Greenhouse-Geisser method. Significant factor effects were further analyzed by the Tukey's honestly significant difference post hoc test.

\section{Results}

\section{Experiment 1: excitation of SNc DA neurons can be as rewarding as that of VTA DA neurons}

Each mouse was placed in a test chamber and given the opportunity to lever press for photostimulation delivered at the SNc or VTA over 15 sessions. We combined the data of all control mice ( $n=18$ ) during sessions $3-7$, after verifying that there is no reliable effect of stimulation region [VTA: $n=12$ vs SNc: $n=6$ ) or the testing order (ICSS test first: $n=7$ vs operant place preference (OPP) test first: $n=11$ ] with $2_{\text {group }} \times 5_{\text {session }}$ ANOVAs. Control mice responded on the active lever $39.3 \pm 5.6$ (mean \pm SEM) times and the inactive lever $9.8 \pm 2.0$ times per session during sessions 3-7 (Fig. 1A), and their lever press levels did not significantly change over the course of five sessions (one-way repeated ANOVAs). We defined that a mouse is a responder if it responded on the active lever $>3$ SDs over the mean lever presses of the control group (Fig. 1A, green dotted-line) at least in three sessions during sessions 3-7. Seven VTA-ChR2 mice learned to self-stimulate over 1000 times per session by session 6, decreased responding during the extinction phase, sessions $8-11$, and reinstated responding during the reacquisition phase, sessions 12-15. Two mice that were intended for VTA-ChR2 stimulation were eliminated from the following analysis because they had probes placed $0.5 \mathrm{~mm}$ or more dorsal to the VTA (Fig. $1 B$ ). Five SNcChR2 mice learned vigorous ICSS, responding on the active lever $>1000$ times by session 6 (Fig. $1 A$, red dots), while responding very little on the inactive lever (mean \pm SEM: $8.1 \pm 5.6$ throughout the experiment). Four SNc-ChR2 mice displayed low response levels (Fig. 1A, orange dots). Eight SNc-ChR2 mice failed to exceed response levels over the control range (data not shown). These differences in response rate appear to be accounted by the 

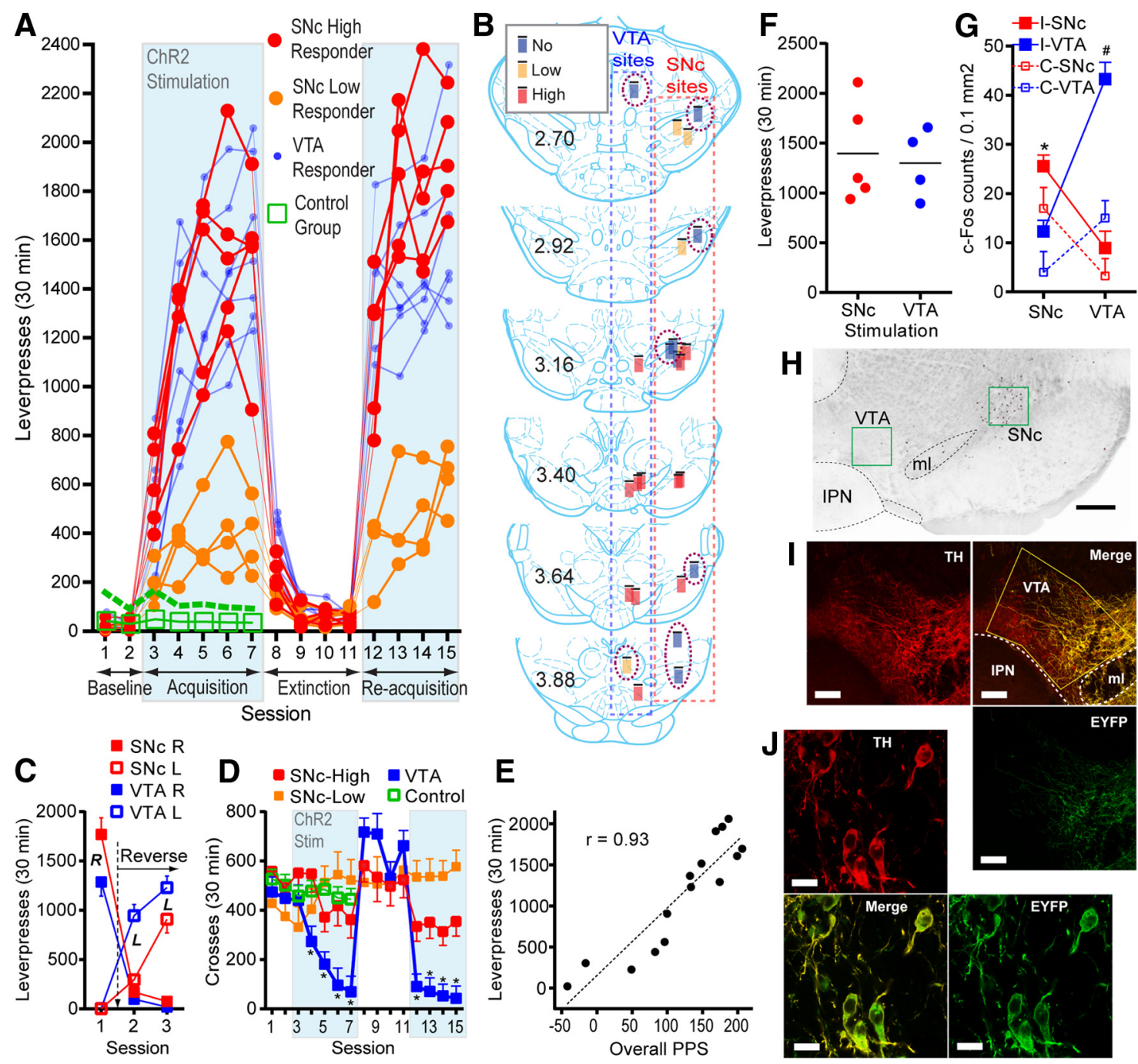

Figure 1. Similar rewarding effects of excitation of SNc and VTA DA neurons. A, Individual ICSS levels (active lever presses) over 15 sessions of SNc-and VTA-ChR2 mice ( $n=9$ and 5 , respectively) and mean lever presses of control group $(n=18)$. Green dotted line indicates 3 SDs above the mean lever presses of the control group. $\boldsymbol{B}, 0$ ptic-fiber placements of ChR2 mice. The tips of optic fibers are shown by black rectangles, and just below, colored rectangles $(0.3 \mathrm{~mm}$ in length) indicate zones most powerfully affected by photostimulation. The red, orange, and blue colors of rectangles indicate high, low, and no responders, respectively. C, Lever presses (means \pm SEM; SNc: $n=5$, VTA: $n=7$ ) before and after reversed assignment of active and inactive levers. ${ }^{R} p<0.005$, right-lever values significantly greater than left-lever values in session 1 and right-lever values in sessions 2 and $3 ;{ }^{L} p<0.005$, left-lever values significantly greater than right-lever values in corresponding sessions and left-lever values in session 1.D, Locomotor activity (means \pm SEM) during ICSS. ${ }^{*} p<0.0005$, VTA value significantly lower from its value of session 1,2 , or 3 . E, Positive correlation between ICSS levels in session 7 (see $\boldsymbol{A})$ and overall PPSs of ChR2 mice $(n=15)$. F, ICSS levels of the mice that received smaller volumes $(0.2-0.3 \mu$ l) of vector injections. $\mathbf{G}$, Differential c-Fos expression between the SNc and VTA. I-SNc and I-VTA signify SNc and VTA stimulation ipsilateral to counting site; C-SNc and C-VTA signify SNc and VTA stimulation contralateral to counting site. ${ }^{*} p<0.05$, The value significantly greater than the corresponding VTA value; ${ }^{*} p<0.005$, The value significantly greater than the corresponding SNc value and I-SNc's VTA value. $\boldsymbol{H}$, Photomicrogram showing c-Fos expression following SNc stimulation. Scale bar, $300 \mu \mathrm{m}$. IPN, Interpeduncular nucleus; ml, medial lemniscus. I, Photomicrograms showing limited colocalization between TH and EYFP neurons within the VTA (defined by yellow line), following a SNc injection. Scale bar, $265 \mu \mathrm{m}$. J, Colocalization of TH and EYFP in SNc neurons. Scale bar, $21 \mu \mathrm{m}$.

optic fiber placement in relation to the location of ChR2expressing DA neurons (Fig. 1B). The placements of nonresponders were generally found in regions just dorsal to the SNc or in the lateral or posterior edges of the SNc. Thus, the response ranges for both SNc and VTA were similarly high when the probe placement was directly over/on the intended site. When active and inactive lever assignment was reversed, both VTA and SNc high-responders quickly reversed responding between the left and right levers (Fig. 1C).

Interestingly, the VTA-ChR2 mice significantly decreased crossing between the two halves of the chamber as they learned ICSS (sessions 3-7 and 12-15), whereas the SNc high responders, which showed comparable ICSS, did not (Fig. 1D; a significant group $\times$ session interaction, $F_{(28,182)}=10.34, p<0.0001$, with a $3_{\text {group }} \times 15_{\text {session }}$ ANOVA).
Optogenetic stimulation can excite or inhibit neurons in a subsecond scale. We took advantage of this property to examine affective effects of the stimulation using an OPP test (Crowder and Hutto, 1992). It is especially difficult to detect punishing effects of DA-neuron inhibition with lever press procedures, and the conventional conditioned placepreference test measures conditioned effects rather than immediate operant reaction to stimuli. First, to determine whether OPP can provide comparable measurement as ICSS, some of the mice tested for ICSS ( 7 from the VTA group and 8 from the SNc group) were subsequently tested for OPP. Overall PPS were significantly correlated with active lever presses in session 7 of the ICSS experiment $(r=0.93, p<0.0001$; Fig. $1 E)$, suggesting that OPP can measure highly similar, if not the same, affective effects as ICSS. 
A
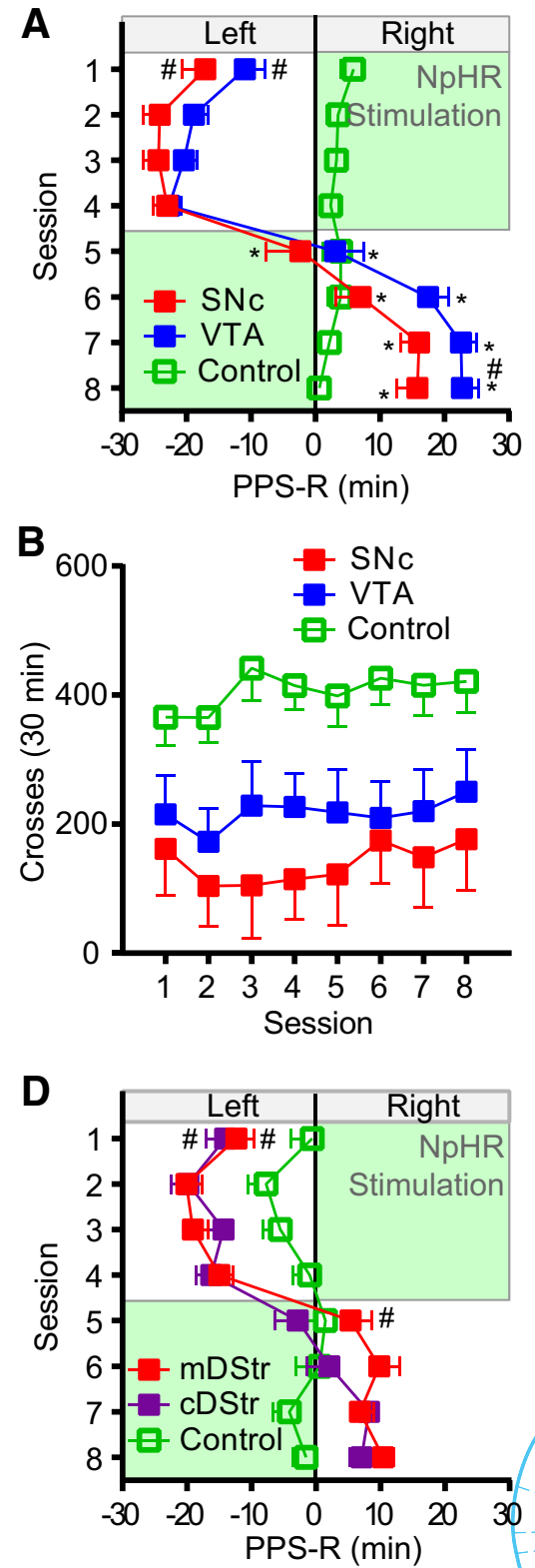

E

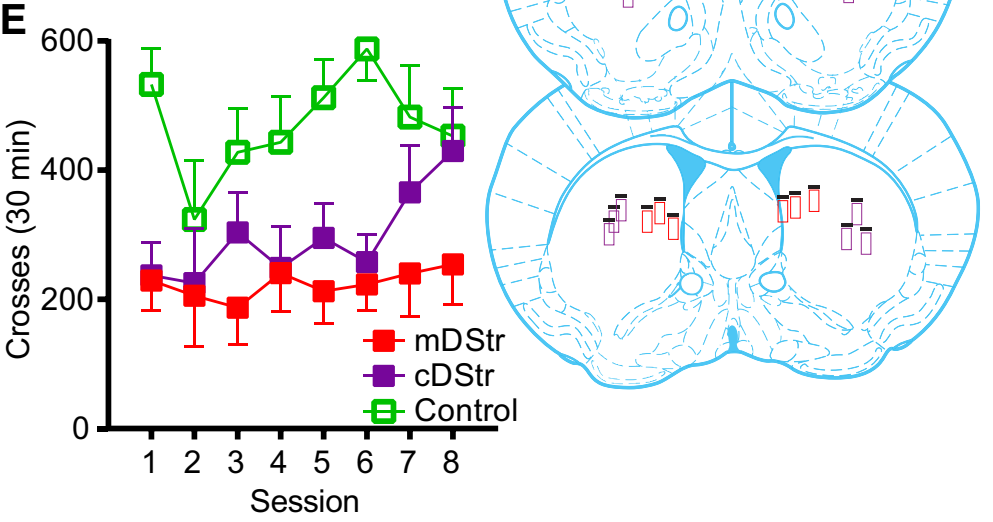

Figure 2. Aversive effects of inhibition of SNc and VTA DA neurons. Continuous photostimulation, shown in green squares, was delivered in the right compartment during sessions $1-4$ and in the left during sessions $5-8$. A, Place avoidance as shown by place-preference score with respect to the right compartment (PPS-R), derived by subtracting left-compartment time from rightcompartment time (means \pm SEM; SNc: $n=7$, VTA: $n=10$, control: $n=19$ ). ${ }^{*} p<0.05$, SNc or VTA session value significantly different from the values in sessions $1-4 ;{ }^{\#} p<0.001$, SNc or VTA values during sessions $1-4$ or $5-6$ significantly different from respective control values. $\boldsymbol{B}$, Locomotor activity (means \pm SEM) during OPP tests. C, Optic-fiber placements of SNc-and VTA-NpHR mice. See Figure $1 B$ legend for description. $\boldsymbol{D}$, Place avoidance induced by inhibition of SNc-DStr DA projections. The data are
Experiment 2: specificity of SNc photostimulation

Experiment 1 involved $1 \mu \mathrm{l}$ vector injections, and $\mathrm{SNc}$ injections resulted in ChR2 expression in many VTA neurons (data not shown), raising a stimulation-specificity issue. To verify that affective effects of $\mathrm{SNc}$ stimulation are indeed mediated through $\mathrm{SNc}$ neurons, we examined effects of smaller volumes of AAV-ChR2 injections $(0.2-0.3 \mu \mathrm{l})$ into the $\mathrm{SNc}$ or VTA. Figure $1 F$ depicts lever presses of the mice that received smaller volumes (SNc: $n=5$; VTA: $n=4$ ) and displayed vigorous ICSS in session 7. A histological analysis revealed that the SNc-ChR2 mice had only $13.1 \pm 2.4 \%$ (mean $\pm \mathrm{SEM}$ ) of VTA TH-positive neurons displayed EYFP expression (Fig. 1I). Figure $1 G$ depicts c-Fos counts in the SNc and VTA following either SNc or VTA photostimulation. $\mathrm{SNc}$ stimulation induced greater c-Fos counts in the SNc than the VTA of the ipsilateral hemisphere (Fig. $1 H$ ), whereas VTA stimulation induced greater Fos counts in the VTA than the $\mathrm{SNc}$ (a significant stimulationregion $\times$ counting-region interaction, $F_{(1,6)}=$ $138.89, p<0.0001$, with a $2_{\text {stimulation-region }} \times$ 2 counting-region ANOVA). Although the mechanisms are not clear, it is interesting to see similar, but much weaker, effects of the stimulation on Fos counts of the contralateral regions (a significant a stimulation-region $\times$ counting-region interaction, $\left.F_{(1,6)}=11.69, p<0.05\right)$. Furthermore, a significant stimulation-region $\times$ countingregion $\times$ hemisphere interaction $\left(F_{(1,6)}=\right.$ 10.49, $p<0.05)$ was revealed with a $2_{\text {stimulation-region }} \times 2_{\text {counting-region }} \times 2_{\text {hemisphere }}$ ANOVA. In addition, we determined $98.8 \%$ of ChR2 neurons are TH-positive (Pearson's coefficient with the JACoP of ImageJ; Fig. 1J; Bolte and Cordelières, 2006).

Experiment 3: OPP tests reveal aversive effects of inhibition of VTA and SNc

\section{DA neurons}

We combined the data on OPP of all control mice $(n=19)$ after verifying that there is no reliable effect of photostimulation region (VTA: $n=12$ vs SNc: $n=7$ ) or the testing order (ICSS test first: $n=7$ vs OPP test first: $n=12 ; 2_{\text {group }} \times 5_{\text {session }}$ ANOVAs). Control mice, which lacked NpHR expression, did not show strong

\section{$\leftarrow$}

mean \pm SEM (mDStr: $n=7$, cDStr: $n=6$, control: $n=5$ ). ${ }^{\#} p<0.05, \mathrm{mDS}$ tr or CDStr values during sessions $1-4$ or $5-8$ significantly different from respective control values. $E$, Locomotor activity (mean \pm SEM) during OPP tests. $\boldsymbol{F}$, Optic-fiber placements of mDStr- and CDStr-NpHR mice. See Figure $1 B$ legend for description. mDStr: unfilled red rectangles; CDStr: unfilled purple rectangles. 
preference between the compartments nor did they change place preference when stimulation compartment changed (Fig. 2A). Both SNc and VTA NpHR mice avoided the right compartment in sessions 1-4 and preferred it in sessions 5-8. These observations were confirmed by significant interactions between group and stimulation-compartment $\left(F_{(2,33)}=99.00, p<0.0001\right)$ and between group, stimulation-compartment and session $\left(F_{(6,99)}=\right.$ $10.15, p<0.0001)$ with a $3_{\text {group }} \times 2_{\text {stimulation-compartment }} \times 4_{\text {session }}$ ANOVA. Figure $2 B$ shows crossing counts between the two compartments during the OPP tests. Both SNc- and VTA-NpHR mice crossed between the compartments less frequently than control mice throughout the experiment (Tukey's test following a significant group effect: $\left.F_{(2,33)}=11.34, p<0.0005\right)$. Figure $2 C$ depicts probe placements of these mice. The data of one subject were not included for the above analyses due to probe misplacement.

\section{Experiment 4: OPP tests reveal aversive effects of inhibition of nigro-striatal DA neurons}

Here, we examined whether inhibition of nigro-striatal DA neurons induces aversive effects. Mice received photostimulation at the mDStr or cDStr. mDStr- and cDStr-NpHR mice $(n=7$ and $n=6$, respectively) avoided the right compartment during sessions $1-4$ and preferred it when photostimulation was delivered to the left during sessions 5-8 (Fig. 2D). Control mice $(n=5)$ did not display strong preference between the two compartments throughout the experiment. These observations are supported by significant interactions between group and stimulation-compartment, $F_{(2,15)}=$ $11.36, p<0.0005$, with a $3_{\text {group }} \times 2_{\text {stimulation-compartment }} \times 4_{\text {session }}$ ANOVA. Moreover, mDStr-NpHR mice crossed between the compartments less frequently than the control group $(p<0.01$; Fig. $2 E)$. A similar trend was found for cDStr-NpHR mice, although their crossing counts were not significantly lower from those of control $\left(p=0.072\right.$; a significant group effect: $\left.F_{(2,15)}=6.40, p<0.01\right)$.

\section{Discussion}

The present study provides evidence that the excitation and inhibition of SNc DA neurons induce reward and aversion, respectively, and the extent of these effects is similar to those of the VTA DA neurons. The rewarding effects following SNc stimulation appear to be mediated by direct excitation of SNc DA neurons, because SNc-ChR2 stimulation results in large c-Fos expression in the SNc and little expression in the VTA, whereas VTA-ChR2 stimulation does the opposite. The notion that our SNc or VTA stimulation activated different sets of neurons is further supported by the observation that SNc- and VTA-ChR2 mice during ICSS displayed different patterns of locomotor activity. The finding that excitation of SNc DA neurons is rewarding is consistent with the Rossi et al. (2013) study that was published while the present study was under consideration for publication. Our data add that stimulation of SNc DA neurons can be as rewarding as that of VTA DA stimulation. Our finding also complements the human research that suggests affective role of the nigro-striatal DA system; in particular, DStr DA release is associated with craving for cocaine (Volkow et al., 2006; Wong et al., 2006). Although research on affective effects of abused drugs has been focused on the mesolimbic DA system, it seems to be important to further investigate how the nigrostriatal DA system possibly participates in affective processes involved in abused drugs.

The present study provides first evidence that inhibition of SNc DA neurons or nigrostriatal DA projections causes aversion like that of VTA DA neurons. Our finding has important implications in understanding Parkinson's disease, characterized by extensive loss of SNc DA neurons, and accompanied by not only movement deficits, but also affective deficits including depression, anhedonia, and apathy (Chaudhuri and Schapira, 2009). Our data raise the possibility that loss of SNc DA neurons is sufficient to cause some of these affective deficits in Parkinson's patients. Consistent with this notion is that the recent report that selective 6-OHDA lesions of SNc DA neurons attenuate escape and avoidance from aversive stimuli (Drui et al., 2013). Moreover, in the VTA, optogenetic excitation and inhibition attenuate and facilitate depression-like symptoms, respectively (Tye et al., 2013). However, roles of DA neurons in affective processes may be more complicated. Optogenetic stimulation of VTA DA neurons during mild social stress potentiates subsequent induction of depression-like behavior (Chaudhury et al., 2013). Thus, activity of DA neurons may interact with ongoing environmental conditions in subsequent behavior.

DA neurons of the VTA and SNc receive different afferents (Watabe-Uchida et al., 2012) and send efferents to different regions (Fallon and Moore, 1978). A recent study has shown that even subgroups of VTA DA neurons defined by distinct afferents and efferents play different functions (Lammel et al., 2012). Future research needs to address how selective excitation and inhibition of subgroups of DA neurons can induce similar affective effects.

\section{References}

Adamantidis AR, Tsai HC, Boutrel B, Zhang F, Stuber GD, Budygin EA, Touriño C, Bonci A, Deisseroth K, de Lecea L (2011) Optogenetic interrogation of dopaminergic modulation of the multiple phases of rewardseeking behavior. J Neurosci 31:10829-10835. CrossRef Medline

Bolte S, Cordelières FP (2006) A guided tour into subcellular colocalization analysis in light microscopy. J Microsc 224:213-232. CrossRef Medline

Chaudhuri KR, Schapira AH (2009) Non-motor symptoms of Parkinson's disease: dopaminergic pathophysiology and treatment. Lancet Neurol 8:464-474. CrossRef Medline

Chaudhury D, Walsh JJ, Friedman AK, Juarez B, Ku SM, Koo JW, Ferguson D, Tsai HC, Pomeranz L, Christoffel DJ, Nectow AR, Ekstrand M, Domingos A, Mazei-Robison MS, Mouzon E, Lobo MK, Neve RL, Friedman JM, Russo SJ, Deisseroth K, Nestler EJ, et al. (2013) Rapid regulation of depression-related behaviours by control of midbrain dopamine neurons. Nature 493:532-536. CrossRef Medline

Crowder WF, Hutto CW Jr (1992) Operant place conditioning measures examined using two nondrug reinforcers. Pharmacol Biochem Behav 41: 817-824. CrossRef Medline

Drui G, Carnicella S, Carcenac C, Favier M, Bertrand A, Boulet S, Savasta M (2013) Loss of dopaminergic nigrostriatal neurons accounts for the motivational and affective deficits in Parkinson's disease. Mol Psychiatry. Advance online publication. Retrieved Feb. 12, 2013. doi:10.1038/ $\mathrm{mp}$.2013.3. CrossRef Medline

Fallon JH, Moore RY (1978) Catecholamine innervation of the basal forebrain: IV. Topography of the dopamine projection to the basal forebrain and neostriatum. J Comp Neurol 180:545-580. CrossRef Medline

Fibiger HC, Phillips AG (1986) Reward, motivation, cognition: psychobiology of mesotelencephalic dopamine systems. In: Handbook of physiology, Vol 4: the nervous system (Mountcastle VB, Bloom FE, Geiger SR, eds), pp 647-675. Bethesda, MD: Am Physiological Society.

Haber SN (2003) The primate basal ganglia: parallel and integrative networks. J Chem Neuroanat 26:317-330. CrossRef Medline

Ikemoto S (2007) Dopamine reward circuitry: two projection systems from the ventral midbrain to the nucleus accumbens-olfactory tubercle complex. Brain Res Rev 56:27-78. CrossRef Medline

Jhou TC, Good CH, Rowley CS, Xu SP, Wang H, Burnham NW, Hoffman AF, Lupica CR, Ikemoto S (2013) Cocaine drives aversive conditioning via delayed activation of dopamine-responsive habenular and midbrain pathways. J Neurosci 33:7501-7512. CrossRef Medline

Keller KL, Vollrath-Smith FR, Jafari M, Ikemoto S (2013) Synergistic interaction between caloric restriction and amphetamine in food-unrelated approach behavior of rats. Psychopharmacology. Advance online publication. Retrieved Oct. 8, 2013. doi:10.1007/s00213-013-3300.9. 
Kim KM, Baratta MV, Yang A, Lee D, Boyden ES, Fiorillo CD (2012) Optogenetic mimicry of the transient activation of dopamine neurons by natural reward is sufficient for operant reinforcement. PLoS One 7:e33612. CrossRef Medline

Koob GF (1992) Drugs of abuse: anatomy, pharmacology and function of reward pathways. Trends Pharmacol Sci 13:177-184. CrossRef Medline

Kravitz AV, Tye LD, Kreitzer AC (2012) Distinct roles for direct and indirect pathway striatal neurons in reinforcement. Nat Neurosci 15:816-818. CrossRef Medline

Lammel S, Lim BK, Ran C, Huang KW, Betley MJ, Tye KM, Deisseroth K, Malenka RC (2012) Input-specific control of reward and aversion in the ventral tegmental area. Nature 491:212-217. CrossRef Medline

Lindeberg J, Usoskin D, Bengtsson H, Gustafsson A, Kylberg A, Söderström S, Ebendal T (2004) Transgenic expression of Cre recombinase from the tyrosine hydroxylase locus. Genesis 40:67-73. CrossRef Medline

Liu ZH, Shin R, Ikemoto S (2008) Dual role of medial A10 dopamine neurons in affective encoding. Neuropsychopharmacology 33:3010-3020. CrossRef Medline

McDonald JH (2009) Handbook of biological statistics, Ed 2. Baltimore: Sparky House.

Robbins TW, Everitt BJ (1996) Neurobehavioural mechanisms of reward and motivation. Curr Op Neurobiol 6:228-236. CrossRef Medline

Rossi MA, Sukharnikova T, Hayrapetyan VY, Yang L, Yin HH (2013) Operant self-stimulation of dopamine neurons in the substantia nigra. PLoS One 8:e65799. CrossRef Medline

Shin R, Cao J, Webb SM, Ikemoto S (2010) Amphetamine administration into the ventral striatum facilitates behavioral interaction with unconditioned visual signals in rats. PLoS One 5:e8741. CrossRef Medline

Shippenberg TS, Bals-Kubik R, Huber A, Herz A (1991) Neuroanatomical substrates mediating the aversive effects of D-1 dopamine receptor antagonists. Psychopharmacology 103:209-214. CrossRef Medline

Sparta DR, Stamatakis AM, Phillips JL, Hovelsø N, van Zessen R, Stuber GD (2012) Construction of implantable optical fibers for long-term optogenetic manipulation of neural circuits. Nat Protoc 7:12-23. CrossRef Medline
Stamatakis AM, Stuber GD (2012) Activation of lateral habenula inputs to the ventral midbrain promotes behavioral avoidance. Nat Neurosci 15: 1105-1107. CrossRef Medline

Tan KR, Yvon C, Turiault M, Mirzabekov JJ, Doehner J, Labouèbe G, Deisseroth K, Tye KM, Lüscher C (2012) GABA neurons of the VTA drive conditioned place aversion. Neuron 73:1173-1183. CrossRef Medline

Tsai HC, Zhang F, Adamantidis A, Stuber GD, Bonci A, de Lecea L, Deisseroth K (2009) Phasic firing in dopaminergic neurons is sufficient for behavioral conditioning. Science 324:1080-1084. CrossRef Medline

Tye KM, Mirzabekov JJ, Warden MR, Ferenczi EA, Tsai HC, Finkelstein J, Kim SY, Adhikari A, Thompson KR, Andalman AS, Gunaydin LA, Witten IB, Deisseroth K (2013) Dopamine neurons modulate neural encoding and expression of depression-related behaviour. Nature 493:537-541. CrossRef Medline

Volkow ND, Wang GJ, Telang F, Fowler JS, Logan J, Childress AR, Jayne M, Ma Y, Wong C (2006) Cocaine cues and dopamine in dorsal striatum: mechanism of craving in cocaine addiction. J Neurosci 26:6583-6588. CrossRef Medline

Watabe-Uchida M, Zhu L, Ogawa SK, Vamanrao A, Uchida N (2012) Whole-brain mapping of direct inputs to midbrain dopamine neurons. Neuron 74:858-873. CrossRef Medline

Wise RA (2009) Roles for nigrostriatal—not just mesocorticolimbic-dopamine in reward and addiction. Trends Neurosci 32:517-524. CrossRef Medline

Witten IB, Steinberg EE, Lee SY, Davidson TJ, Zalocusky KA, Brodsky M, Yizhar O, Cho SL, Gong S, Ramakrishnan C, Stuber GD, Tye KM, Janak PH, Deisseroth K (2011) Recombinase-driver rat lines: tools, techniques, and optogenetic application to dopamine-mediated reinforcement. Neuron 72:721-733. CrossRef Medline

Wong DF, Kuwabara H, Schretlen DJ, Bonson KR, Zhou Y, Nandi A, Brasić JR, Kimes AS, Maris MA, Kumar A, Contoreggi C, Links J, Ernst M, Rousset O, Zukin S, Grace AA, Lee JS, Rohde C, Jasinski DR, Gjedde A, London ED (2006) Increased occupancy of dopamine receptors in human striatum during cue-elicited cocaine craving. Neuropsychopharmacology 31:2716-2727. CrossRef Medline 